\title{
Glucose affects monocarboxylate cotransporter (MCT) 1 expression during mouse preimplantation development
}

\author{
Sarah Jansen, Tahereh Esmaeilpour, Marie Pantaleon and Peter L Kaye \\ School of Biomedical Sciences, University of Queensland, Brisbane 4072, QLD, Australia \\ Correspondence should be addressed to PL Kaye; Email: p.kaye@uq.edu.au
}

T Esmaeilpour is now at Research Center of Cell and Molecular Biology, School of Medicine, Shahid Beheshti, Tehran, Iran

\begin{abstract}
Cleavage-stage embryos have an absolute requirement for pyruvate and lactate, but as the morula compacts, it switches to glucose as the preferred energy source to fuel glycolysis. Substrates such as glucose, amino acids, and lactate are moved into and out of cells by facilitated diffusion. In the case of lactate and pyruvate, this occurs via $\mathrm{H}^{+}$-monocarboxylate cotransporter (MCT) proteins. To clarify the role of MCT in development, transport characteristics for DL-lactate were examined, as were mRNA expression and protein localisation for MCT1 and MCT3, using confocal laser scanning immunofluorescence in freshly collected and cultured embryos. Blastocysts demonstrated significantly higher affinity for DL-lactate than zygotes $\left(K_{\mathrm{m}} 20 \pm 10\right.$ vs $87 \pm 35 \mathrm{mmol}$ lactate/l; $\boldsymbol{P}=\mathbf{0 . 0 3}$ by linear regression) but was similar for all stages. For embryos derived in vivo and those cultured with glucose, MCT1 mRNA was present throughout preimplantation development, protein immunoreactivity appearing diffuse throughout the cytoplasm with brightest intensity in the outer cortical region of blastomeres. In expanding blastocysts, MCT1 became more prominent in the cytoplasmic cortex of blastomeres, with brightest intensity in the polar trophectoderm. Without glucose, MCT1 mRNA was not expressed, and immunoreactivity dramatically reduced in intensity as morulae died. MCT3 mRNA and immunoreactivity were not detected in early embryos. The differential expression of MCT1 in the presence or absence of glucose demonstrates that it is important in the critical regulation of $\mathrm{pH}$ and monocarboxylate transport during preimplantation development, and implies a role for glucose in the control of MCT1, but not MCT3, expression.
\end{abstract}

Reproduction (2006) 131 469-479

\section{Introduction}

It is well established that glucose cannot support development of the preimplantation mouse embryo prior to compaction (Brinster \& Thomson 1966). Freshly collected cleavage stage embryos preferentially consume pyruvate before switching to glucose as the major energy substrate during compaction and blastocyst formation (Leese \& Barton 1984). The same phenomenon has been observed in embryos cultured in vitro (Gardner \& Leese 1986). While preferred, the reliance of morulae on glucose-derived energy is not absolute, as two-cell embryos cultured in the absence of glucose may still form blastocysts by increasing their rate of consumption of pyruvate to meet the energy demands of cavitation (Martin \& Leese 1999).

In contrast, freshly fertilised zygotes deprived of glucose from about $16-18 \mathrm{~h}$ after administration of human chorionic gonadotrophin (hCG) (i.e. $24 \mathrm{~h}$ earlier) cleave to form morulae in vitro, but fail to form blastocysts and subsequently degenerate (Chatot et al. 1989, Brown \& Whittingham 1991, Martin \& Leese 1995). These 'glucose-starved' embryos do not develop the capacity to utilise glucose preferentially or to increase pyruvate utilisation to compensate (Chatot et al. 1989, Brown \& Whittingham 1991, Martin \& Leese 1995). Glucose exposure during mouse preimplantation development therefore presents an intriguing paradox. While not required as an energy substrate (Leese \& Barton 1984), there is an absolute requirement for exposure to glucose prior to the eightcell stage for blastocyst formation to occur (Chatot et al. 1994, Martin \& Leese 1995). This exposure facilitates expression of the glucose transporter protein (GLUT3) (Pantaleon et al. 2001a), which is essential for blastocyst formation (Pantaleon et al. 1997a) and the adaptive responses associated with increased pyruvate utilisation that must occur in the absence of glucose. Therefore, once exposed to glucose, embryos can adjust to its absence (Martin \& Leese 1995), suggesting that glucose, rather than as a nutrient per se, may act as a signal during early cleavage that induces metabolic differentiation of the developing embryo. Thus, while not providing a large proportion of ATP to cleavage-stage embryos, glucose may 
permit expression of metabolic enzymes and transporters in compacting morulae, capable of generating the energy required for blastocyst formation. Currently, little is known about the expression and function of pyruvate/lactate transporter proteins, or how they may be regulated in early development.

This study examines the expression of specific $\mathrm{H}^{+}$-monocarboxylate cotransporter (MCT) proteins that facilitate the coupled diffusion of a proton and a monocarboxylate ion (e.g. pyruvate, lactate, acetoacetate or $\beta$-hydroxybutyrate). The 14 identified MCT proteins are predicted to have 12 transmembrane $\alpha$-helical domains with cytoplasmic $\mathrm{N}$ - and C-termini (Price et al. 1998, Halestrap \& Price 1999, Halestrap \& Meredith 2004). It is presumed that cellular monocarboxylate homeostasis is regulated by the varying substrate affinities, coupled with distinct cellular and subcellular distributions, in a manner analogous to glucose homeostasis (Halestrap 1976, Gould \& Holman 1993, Halestrap \& Price 1999). MCT1-4 are the best-characterised isoforms to date. The transport kinetics of MCT, by fluorescence measurement of changing $\mathrm{pH}$, and mRNA expression of these isoforms in mouse embryos, have been examined previously with varying results (Harding et al. 1999, Herubel et al. 2002).

MCT transport was therefore assessed by radiotracer flux at physiologic $\mathrm{pH}$, and MCT1 and MCT3 were examined for mRNA and protein expression. In retinal pigment epithelium, MCT1 (apical) and MCT3 (basolateral) cooperate to transfer $\mathrm{H}^{+}$and lactate from the highly glycolytic retina to the choroid (Philp et al. 1998, 2001, 2003a). Because this reflects the glycolytic activity of morulae and blastocysts, these isoforms were selected to determine whether a similar cooperative mechanism exists for lactate efflux from the blastocoel cavity to the maternal interface. We characterised expression and localisation of MCT1 and MCT3 in mouse embryos developing in vivo or with and without glucose in vitro to clarify their regulation and function in preimplantation development.

\section{Materials and Methods}

\section{Ethics}

All experiments on mice were approved by the Animal Ethics and Experimentation Committees of the University of Queensland. These committees are approved by the National Health and Medical Research Council of Australia.

\section{Antisera \\ Affinity purified anti-MCT1 IgG was raised in goats against a synthetic peptide mapping to the carboxyl terminus of the mouse peptide (Santa Cruz Biotechnology (cat. no. sc- 14917), Santa Cruz, CA, USA). Affinity purified anti-MCT3 antiserum (courtesy N Philp, Thomas Jefferson University, Philadelphia, PA, USA) was raised in New Zealand White rabbits against mouse MCT3 (Philp et al. 2003a). Second-}

ary antibodies included FITC-conjugated rabbit antigoat IgG (Calbiochem-Novachem, San Diego, USA), Texas Red-conjugated goat antirabbit IgG (Calbiochem), horseradish peroxidase-labelled donkey antirabbit $\lg \mathrm{G}$ (Amersham) or rabbit antigoat IgG (Progen Biosciences, Brisbane, Australia).

\section{Embryo collection and culture}

Female Quackenbush mice 6-8 weeks of age were injected i.p. with $10 \mathrm{IU}$ pregnant mare serum gonadotrophin (PMSG) (Folligon; Intervet P/L, Bendigo, Australia) followed $48 \mathrm{~h}$ later with $10 \mathrm{IU}$ hCG i.p. (Chorulon; Intervet). Mated females were killed by cervical dislocation, and embryos were collected 24, 48, 72 and $96 \mathrm{~h}$ after hCG into M2 medium (Fulton \& Whittingham 1978) lacking glucose (M2-G) and modified to contain $0.33 \mathrm{mmol}$ sodium pyruvate/l and $4 \mathrm{~g}$ BSA/l (Hobbs \& Kaye 1985). Cumulus cells were released by incubation with $0.5 \mathrm{~g}$ hyaluronidase/l in M2-G followed by washing in fresh M2-G.

In experiments requiring in vitro derived embryos, zygotes were collected and denuded at $18 \mathrm{~h}$ after hCG for culture in microdroplets at a density of $1 \mathrm{embryo} / \mu \mathrm{l}$ under mineral oil at $37^{\circ} \mathrm{C}$ in a MINC incubator (Cook, Brisbane, Australia) in $5 \% \mathrm{O}_{2}, 5 \% \mathrm{CO}_{2}$ and $90 \% \mathrm{~N}_{2}$. The culture medium used was KSOM (Lawitts \& Biggers 1993) modified to be either glucose free (KSOM-G) or containing $0.6 \mathrm{mmol}$ glucose $/ \mathrm{l}(\mathrm{KSOM})$. One subset of embryos in $\mathrm{KSOM}-\mathrm{G}$ received a brief ( $3 \mathrm{~h}$ ) exposure to $27 \mathrm{mmol}$ glucose/l at 58-60 h after hCG, referred to in the following text as a glucose 'pulse'. They were then washed three times and returned to culture in $\mathrm{KSOM}-\mathrm{G}$ for the remaining period. Control cultured embryos (KSOM) were sampled at 48, 72, 90 and $96 \mathrm{~h}$ after hCG, and embryos cultured in the $\mathrm{KSOM}-\mathrm{G}$ and 'pulsed' groups were selected at $90 \mathrm{~h}$ after hCG for transport assays and immunohistochemistry. Both KSOM and KSOM-G groups were also sampled 96, 105 and $112 \mathrm{~h}$ for immunohistochemical analysis.

\section{$\left.{ }^{3} \mathrm{H}\right] D L-L a c t a t e$ transport assay}

Embryos were washed and preincubated in lactate-free M2-G (pH 7.4) for $30 \mathrm{~min}$ at $37^{\circ} \mathrm{C}$. To measure DL-lactate uptake, freshly collected two-cell embryos and blastocysts were incubated at $37^{\circ} \mathrm{C}$ or $4{ }^{\circ} \mathrm{C}$ under paraffin oil in $10 \mu \mathrm{l}$ microdroplets of $\mathrm{M} 2-\mathrm{G}$ containing $37 \mathrm{GBq}$ lactic acid, sodium salt, $\left[{ }^{2-3} \mathrm{H}\right] \mathrm{DL}$-lactate, $0.74 \mathrm{TBq} \mathrm{mmol} \mathrm{l} / 1$, and 0.1 , 5, 25, 40 and $50 \mathrm{mmol}$ DL-lactate/l. Osmolarity was maintained by adjusting $\mathrm{NaCl}$ as necessary, and $\mathrm{pH}$ was corrected to 7.4. Triplicate samples of three embryos were removed from incubation and washed four times in icecold M2, and radioactivity was determined as previously described (Gardner \& Kaye 1995).

\section{mRNA analysis}

Embryos were collected at 24, 48, 72 and $96 \mathrm{~h}$ after hCG, and total RNA was obtained by phenol/chloroform 
extraction with the RNeasy Mini Kit (Qiagen). RNA was also extracted from mouse retina, and $1 \mu \mathrm{g}$ total RNA was used for reverse transcription (RT). RNA was reverse transcribed and amplified by PCR (Arcellana-Panlilio \& Schultz 1993) in the presence of specific primers for MCT1 and MCT3. The primer pairs derived from the murine MCT1 and MCT3 CDNA sequences were as follows: MCT1 $5^{\prime}$ primer, 5'-gcctgagcaagtcaagctag- $3^{\prime}$, and $3^{\prime}$ primer, 5'-tcagacctcggatccagtac-3'; MCT3 $5^{\prime}$ primer, $5^{\prime}$-catcttctaccttgctggct- $3^{\prime}$, and $3^{\prime}$ primer, $5^{\prime}$ gttagaccctgttcacagtg- $3^{\prime}$. The $375 \mathrm{bp}$ and $391 \mathrm{bp}$ PCR products for MCT1 and MCT3 respectively were resolved on $2 \%$ agarose gels containing $0.5 \mathrm{mg}$ ethidium bromide/l. Genomic contamination of cDNA samples was tested by parallel PCR for mouse $\beta$-actin with a primer pair that generates a predicted $243 \mathrm{bp}$ fragment for the cDNA and a $330 \mathrm{bp}$ fragment if contaminating genomic DNA is present (Telford et al. 1990).

\section{Immunofluorescence}

Embryos were fixed in 2\% paraformaldehyde in PBS ( $\mathrm{pH} 7.4$ ) and processed for immunofluorescence as previously described (Pantaleon et al. 1997b). Briefly, embryos were incubated overnight at $4{ }^{\circ} \mathrm{C}$ in primary antibody $(2-10 \mathrm{mg} / \mathrm{l})$ and exposed to secondary antisera for $1 \mathrm{~h}$ at room temperature prior to mounting in glycerol for examination with a Bio-Rad (Hercules, CA, USA) MRC2000 confocal laser scanning microscope mounted on a Zeiss (Oberkochen, Germany) Axioskop equipped with a Zeiss Plan-Apochromat $\times 60$ oil-immersion objective. Negative controls for immunofluorescence included normal goat or rabbit serum diluted to the same concentration as primary antibody and omission of primary and secondary antisera.

\section{Western immunoblotting}

Tissues were homogenised in ice-cold homogenisation buffer $(50 \mathrm{mmol}$ Tris- $\mathrm{HCl} / \mathrm{l}, 150 \mathrm{mmol} \mathrm{NaCl} / \mathrm{l}, 10 \mathrm{mmol} \mathrm{NaF} / \mathrm{l}$, $1 \mathrm{mmol} \mathrm{Na} \mathrm{VO}_{4} / \mathrm{l}, 1 \%$ (v/v) Triton X 100 and one complete protease inhibitor tablet $/ 50 \mathrm{ml}$ (Roche)) and centrifuged at $14000 \mathrm{~g}$ for $15 \mathrm{~min}$ at $4{ }^{\circ} \mathrm{C}$. Supernatant was removed and mixed with an equal volume of Laemmli sample buffer (10\% SDS containing 1\% (v/v) glycerol, 0.125 g bromophenol blue/l, $0.125 \mathrm{~g}$ xylene cyanol/l, $100 \mathrm{mmol}$ dithiothreitol/l and $125 \mathrm{mmol}$ Tris- $\mathrm{HCl} / \mathrm{l}(\mathrm{pH}$ 6.8) (Laemmli 1970). Samples $(10 \mu \mathrm{g}$ protein/lane as determined by bicinchoninic acid assay) were separated by polyacrylamide electrophoresis and transferred to $0.45 \mu \mathrm{m}$ Immobilon-P PVDF membrane (Millipore Australia P/L, Sydney, Australia), using Towbin transfer buffer (25 mmol Tris/l, 192 glycine mmol/l, 20\% (v/v) methanol ( $\mathrm{pH} 8.3$ ) (Towbin et al. 1979). Membranes were incubated for $1 \mathrm{~h}$ at room temperature in blocking solution of $5 \%$ skim milk (MCT1) or 5\% BSA (MCT3) in PBS/0.1\% Tween 20. Primary antisera $(0.2 \mathrm{mg} / \mathrm{l})$ were applied overnight at $4{ }^{\circ} \mathrm{C}$, and membranes were exposed to secondary antibody for $1 \mathrm{~h}$ at room temperature. Proteins were visualised with Supersignal West Pico Enhanced Chemiluminescence Detection Kit (Pierce Biotechnology, Rockford, IL, USA).

\section{Statistics}

Kinetic parameters of $\left[{ }^{3} \mathrm{H}\right] \mathrm{DL}$-lactate transport were determined by non-linear regression with Prism (GraphPad Software, Inc., CA, USA). Values presented are means \pm S.E.M. for a series of three experiments per embryo stage or culture type. Since each data point was produced from up to nine embryos, the values were averaged to provide results for each experiment. Statistical testing of differences between $K_{\mathrm{m}}$ and $V_{\max }$ was by Student's $t$-test with Welch's correction for unequal variance.

\section{Results}

\section{$\left[{ }^{3} \mathrm{H}\right] \mathrm{DL}$-Lactate uptake in preimplantation embryos}

Uptake of DL-lactate by two-cell embryos and blastocysts was determined over 25 min (Fig. 1). Radioactivity was detected just above background levels at $0.1 \mathrm{mmol}$ DL-lactate/l. Transport equilibrium was apparent by $12 \mathrm{~min}$ with 5 and $25 \mathrm{mmol}$ DL-lactate/l in two-cell embryos and $5 \mathrm{mmol}$ DL-lactate/l in blastocysts, but may not have been
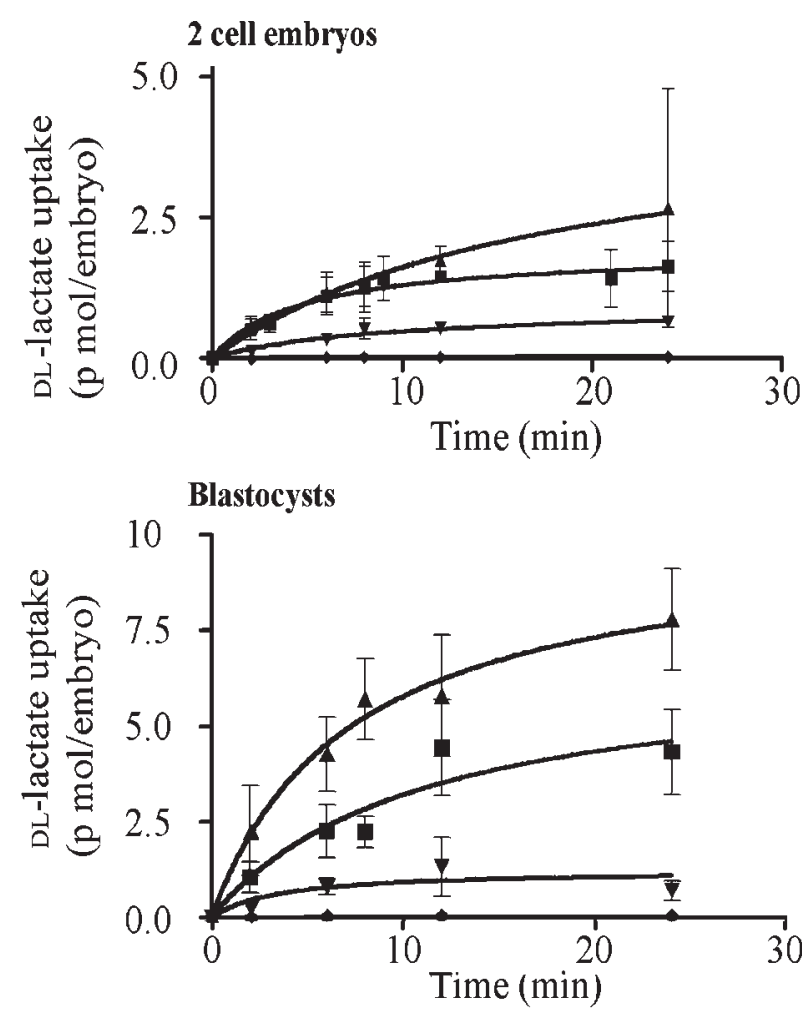

Figure 1 DL-Lactate uptake in mouse embryos. Uptake of DL-lactate by two-cell mouse embryos and blastocysts. Lactate concentrations: (solid diamond) 0.1, (solid inverted triangle) 5, (solid square) 25 and (solid triangle) $50 \mathrm{mmol} / \mathrm{I}$. Each point represents mean \pm S.E.M. for four separate experiments; $n=32$ observations per data point. 
complete by $25 \mathrm{~min}$ with $50 \mathrm{mmol}$ DL-lactate/l. The initial rate was approximately constant up to $5 \mathrm{~min}$ in all concentrations over $0.1 \mathrm{mmol}$ DL-lactate/l. This uptake time was used for subsequent kinetic studies.

At each stage, the initial rate of DL-lactate uptake showed a relationship with DL-lactate concentration best described by the Michaelis-Menten equation (Fig. 2). Zygote uptake showed a $K_{\mathrm{m}}$ almost fourfold higher than blastocysts (Table 1$)(P=0.03$ by linear regression). This trend of increased affinity with development was apparent in morulae, but was not significant $(P=0.06$ by linear regression). $V_{\max }$ did not change during preimplantation development (Table 1). Furthermore, there was no difference in transport characteristics between embryos developing in vivo or in vitro, or between embryos cultured with and without glucose or receiving a glucose pulse (results not shown).

\section{MCT1 and MCT3 expression}

MCT1 protein (Fig. 3A-D) showed diffuse staining throughout the cytoplasm at all preimplantation stages, with apparently brighter intensity in the plasma membrane and outer cortical region of zygotes and two-cell embryos. In blastocysts, the cytoplasms of both inner cell mass (ICM) and trophectoderm (TE) were richly stained for MCT1. Normal goat serum controls for MCT1 (Fig. 3K and L) revealed no specific autofluorescence or immunofluorescence. Immunoreactivity for MCT3 (Fig. 3E-H) was not different from normal rabbit serum-treated control embryos (Fig. 3I and J), suggesting that MCT3 is not expressed during preimplantation development. In agreement with protein expression data, MCT1 mRNA was detected in zygotes, two-cell embryos, morulae and blastocysts (Fig. 4A), while MCT3 mRNA was not detected in embryos (Fig. 4B).

Western blotting demonstrated that both MCT antibodies were monospecific with molecular mass of

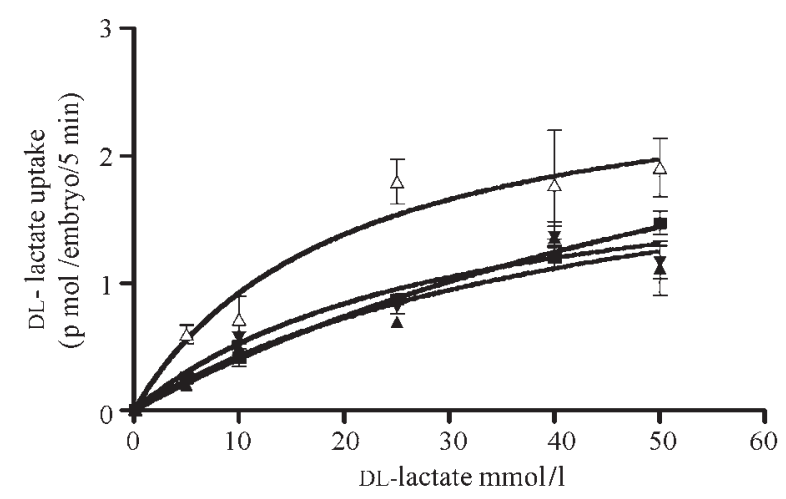

Figure 2 DL-Lactate uptake kinetics in mouse embryos. At each stage, the initial rate of DL-lactate uptake (over $5 \mathrm{~min}$ ) as a function of DL-lactate concentration was fitted by the least-squares analysis to the Michaelis-Menten equation for oocytes (solid square), two-cell embryos (solid triangle), morulae (inverted solid triangle) and blastocysts (open triangle). Each point represents mean \pm S.E.M. for 12 experiments; $n=27$ observations per data point.
Table $1 V_{\max }$ and $K_{\mathrm{m}}$ of DL-lactate transport in embryos.

\begin{tabular}{lcccc}
\hline & Zygote & $\begin{array}{c}\text { Two-cell } \\
\text { embryo }\end{array}$ & Morula & Blastocyst \\
\hline$V_{\max }(\mathrm{pmol} /$ & $4.0 \pm 1.1$ & $2.4 \pm 0.9$ & $2.1 \pm 0.3$ & $2.8 \pm 0.6$ \\
$\begin{array}{l}\text { embryo/5 min }) \\
K_{\mathrm{m}}(\mathrm{mmol} / \mathrm{l})\end{array}$ & $87 \pm 35^{*}$ & $47 \pm 30$ & $30 \pm 10$ & $20 \pm 10^{*}$ \\
\hline
\end{tabular}

$* P=0.03$; data calculated from Fig. 2 .

approximately $45 \mathrm{kDa}$ for MCT1 (Fig. 5A) and $51 \mathrm{kDa}$ for MCT3 (Fig. 5B).

\section{Effect of culture on MCT expression}

Embryos cultured from $18 \mathrm{~h}$ after hCG were selected at 48, 72 and $96 \mathrm{~h}$ after hCG and pooled for RNA extraction and RT-PCR, or fixed for immunolocalisation of MCT1 and MCT3. Protein localisation was not changed by 30 and $54 \mathrm{~h}$ of culture (Fig. 6A-C). After $78 \mathrm{~h}$, cultured blastocysts demonstrated a more diffuse distribution of MCT1 in the cytoplasm of TE and ICM cells. However, staining was present in nuclei in direct contrast to cleavage-stage embryos, and blastocysts that had developed in vivo (compare Fig. 3D with Fig. 6C). MCT1 mRNA was still detected in embryos after 30, 50 and $78 \mathrm{~h}$ of culture (Fig. 6D). MCT3 protein was not present in cultured embryos, and mRNA was not detected at any stage (results not shown).

\section{Effect of glucose on MCT expression in vitro}

Zygotes (18 h after hCG) were randomly assigned for culture in KSOM or KSOM-G. Half of the KSOM-G embryos received a glucose 'pulse' at 58-60 h after hCG (four-cell stage). Morulae (90 h after hCG) were selected and either fixed and stained for MCT1 and MCT3, or pooled in groups of 100 embryos for RNA extraction and RT-PCR. MCT1 protein appeared to be expressed at similar intensity in all three culture groups at $90 \mathrm{~h}$ after hCG (Fig. 7A-D). However, in the complete absence of glucose, mRNA for MCT1 was not detected in the morulae. This loss of MCT1 mRNA expression in the absence of glucose was rescued by a glucose 'pulse' (Fig. 7E). MCT3 protein was absent from embryos in all three culture conditions, and MCT3 mRNA was not expressed (results not shown).

The discrepancy in protein and mRNA expression for MCT1 in the absence of glucose prompted follow-on culture experiments with and without glucose to investigate whether MCT1 protein persisted in the absence of glucose and RNA message. Immunoreactivity for MCT1 diminished in the absence of glucose at 105 and $112 \mathrm{~h}$ after hCG (Fig. 8E-H) coincident with death of the morulae (Fig. 8H). Interestingly, as blastocysts expanded and hatched in the presence of glucose, MCT1 expression became more intense in the polar TE (Fig. 8B-D). Nuclear MCT1, usually detected $96 \mathrm{~h}$ after hCG, was absent by 112 h (Fig. 8D). 
A

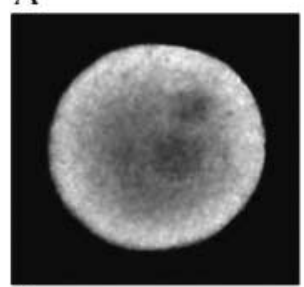

E

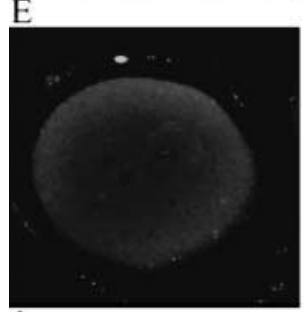

I

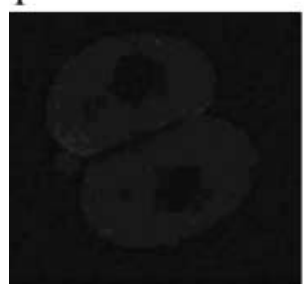

B

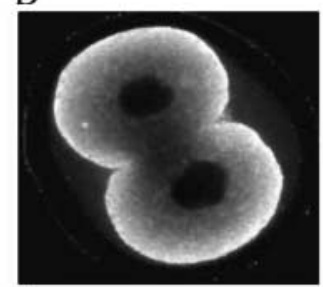

$\mathrm{F}$

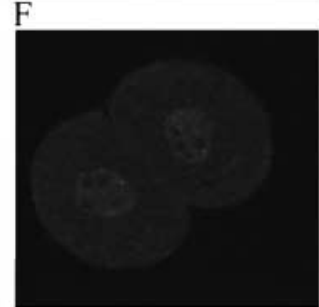

$\mathrm{J}$

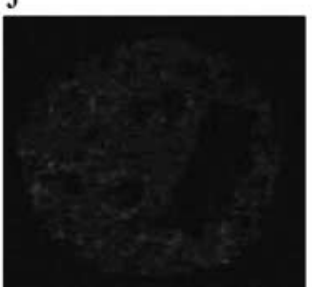

C

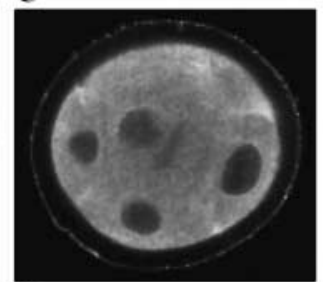

G

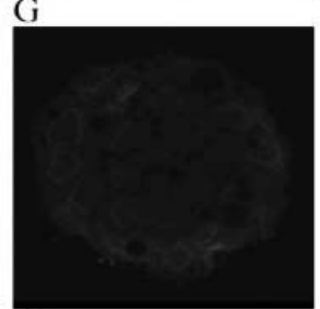

$\mathrm{K}$

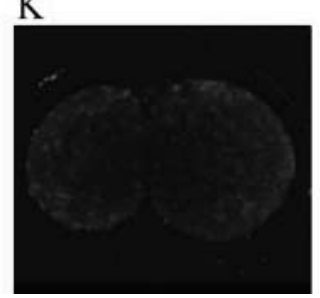

D

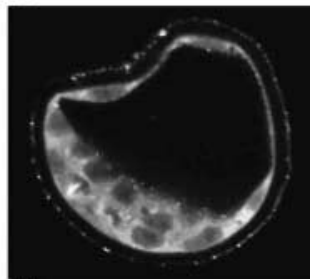

$\mathrm{H}$

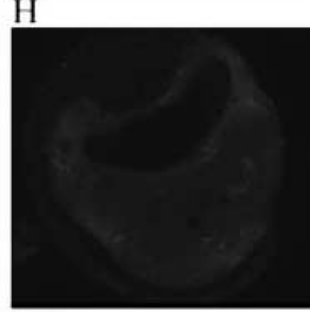

L

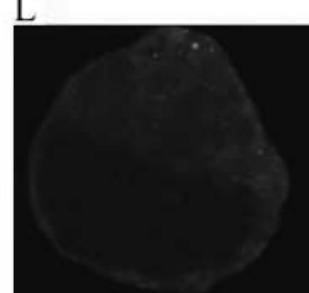

Figure 3 MCT protein expression in freshly collected mouse embryos. Freshly collected embryos (24, 48, 72 and $96 \mathrm{~h}$ after hCG) treated with goat antimouse MCT1 (A-D) or with rabbit antimouse MCT3 (E-H) antisera followed with appropriate secondary antibodies. Immunoreactivity for MCT1 is diffuse in the cytoplasm throughout preimplantation development (A-D) but more intense in the outer cortex of zygotes (A) and two-cell embryos (B). MCT3 (E-H) demonstrates a pattern and intensity of immunoreactivity that is similar to normal serum controls, suggesting that protein may not be present in the embryo. No background immunofluorescence or autofluorescence is evident in normal rabbit serum (I and J) or normal goat serum ( $\mathrm{K}$ and L) controls. Magnification $\sim \times 200$.

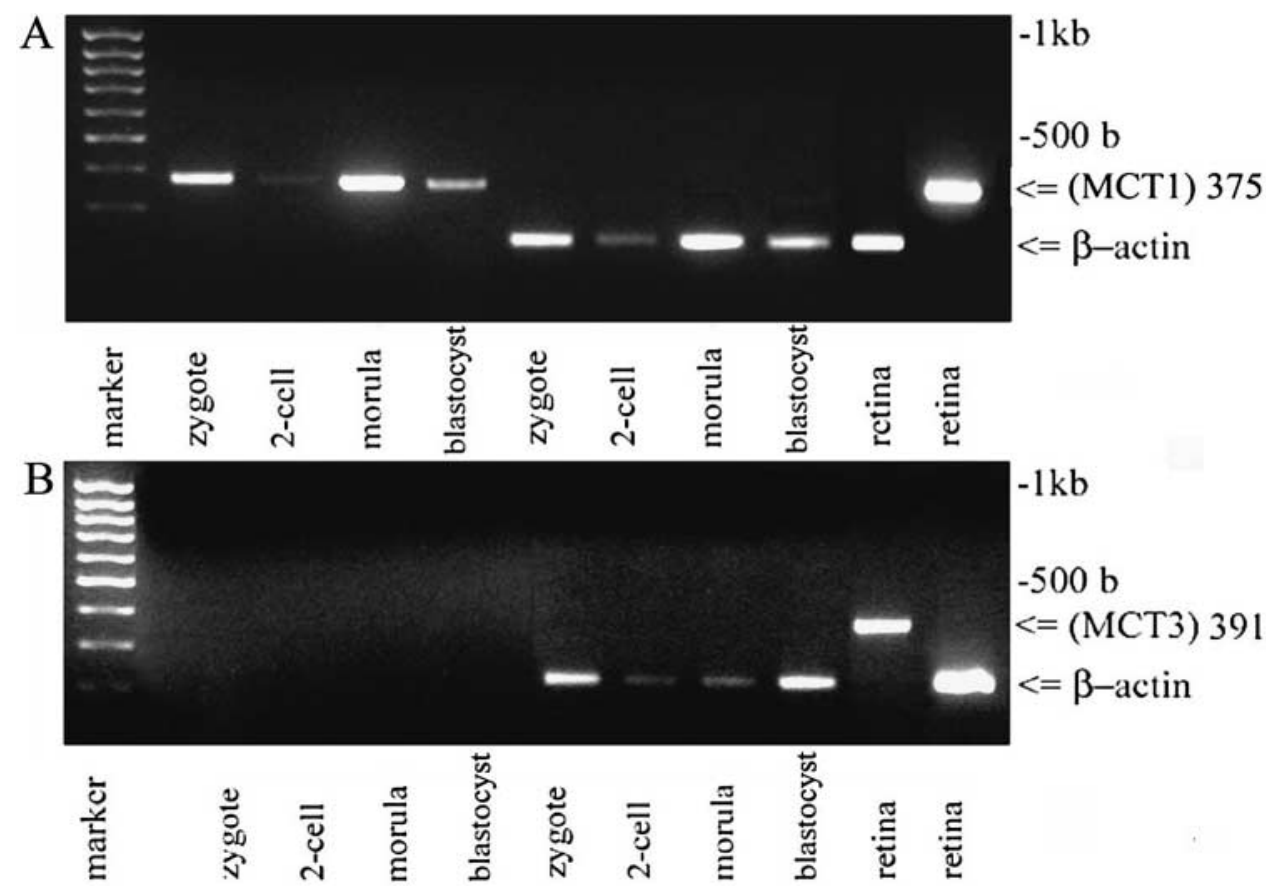

Figure $4 \mathrm{MCT}$ mRNA expression in freshly collected mouse embryos. Freshly collected embryos $(24,48,72$ and $96 \mathrm{~h}$ after hCG) were pooled in groups of 100 for RT-PCR. MCT1 mRNA was detected throughout development (A), consistent with protein expression data, while MCT3 mRNA could not be detected (B). 
A

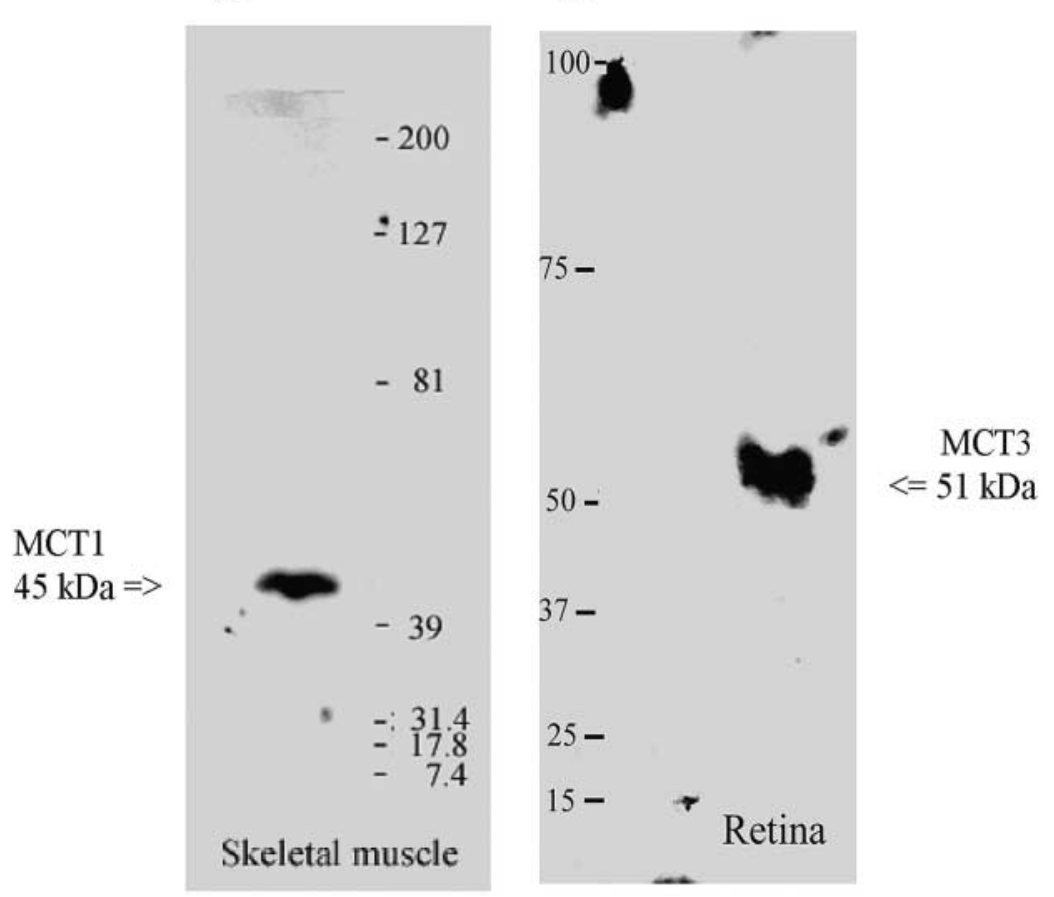

Figure 5 Western blots of MCT antisera. Western blots for both MCT antisera on mouse tissues. Antisera demonstrated monospecificity, with single bands corresponding to molecular mass around $45 \mathrm{kDa}$ for MCT1 (A) and $51 \mathrm{kDa}$ for MCT3 (B).

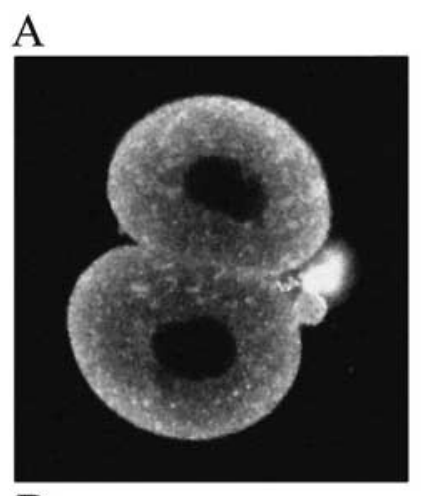

B

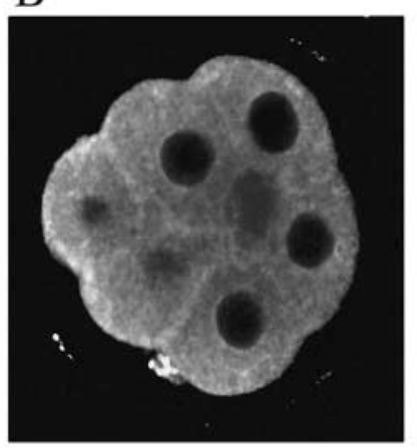

D

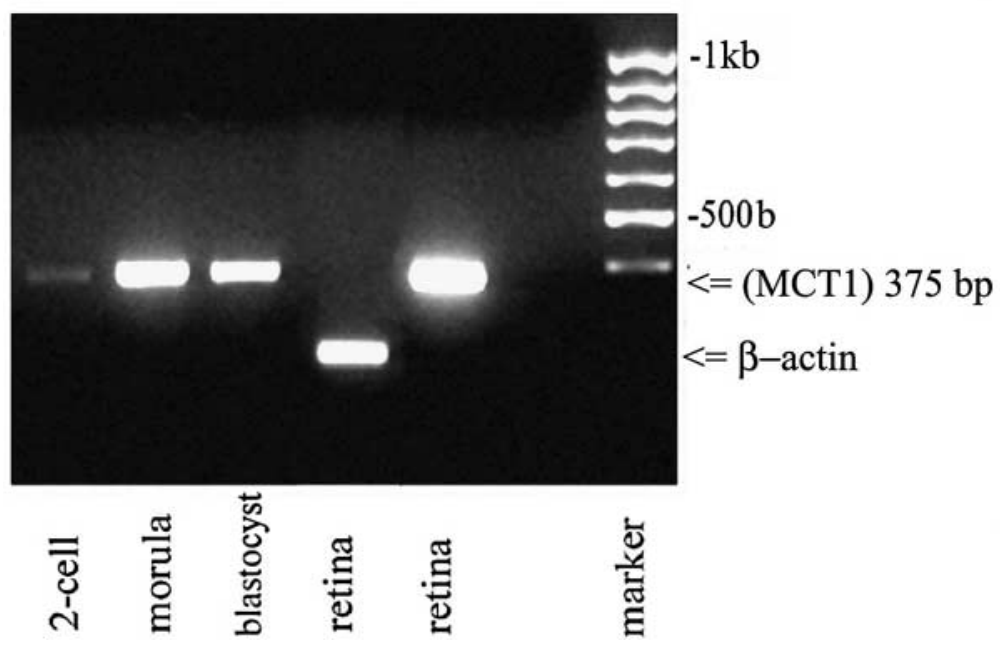

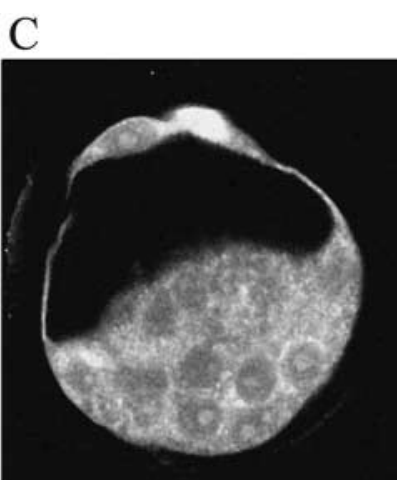

Figure 6 Effect of embryo culture on MCT expression. Zygotes (18 $\mathrm{h}$ after hCG) were cultured in KSOM. Two-cell embryos, morulae and blastocysts were sampled at 48, 72 and $96 \mathrm{~h}$ after hCG respectively for immunohistochemical analysis with MCT1 antisera (A-C)

Magnification $\sim \times 300$. MCT1 was found in the nucleus of cells in the TE and ICM of blastocysts (C), a phenomenon not observed for blastocysts derived in vivo. No other changes in protein expression were apparent between in vitro and in vivo derived embryos for MCT1. Some cultured embryos were pooled in groups of 100 for RT-PCR. MCT1 mRNA was expressed throughout in vitro preimplantation development (D). 

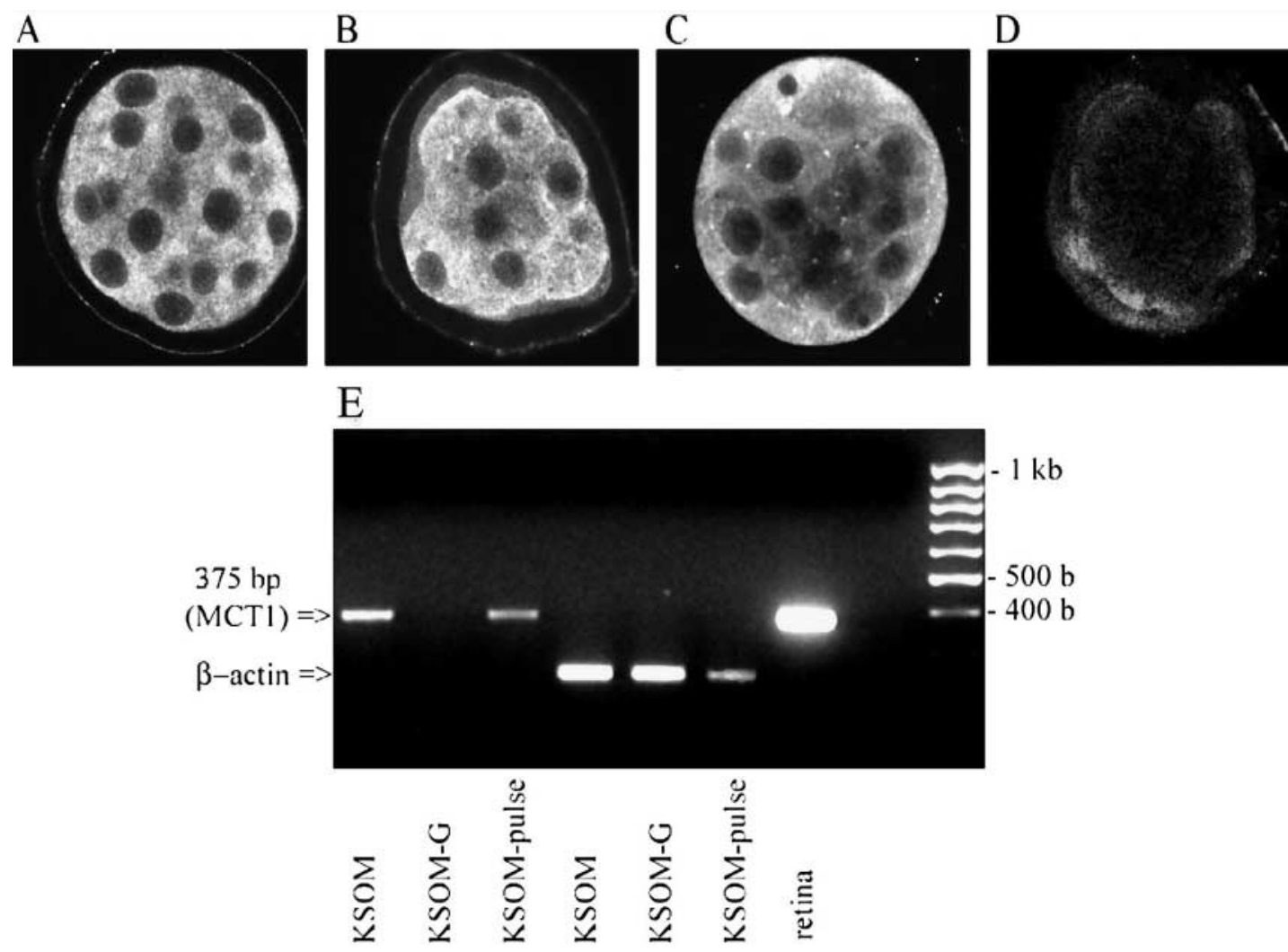

Figure 7 Effect of glucose on MCT1 expression in cultured mouse morulae. Zygotes (18 h after hCG) were cultured in KSOM or KSOM-G, or received a glucose 'pulse' at 58-60 h after hCG. Compact morulae were selected at $90 \mathrm{~h}$ after hCG for immunohistochemical analysis of MCT1 (A-C) or normal serum control (D), or were pooled in groups of 100 for RT-PCR to detect MCT1 (E). Without glucose, MCT1 protein appears to be expressed at similar intensity at $90 \mathrm{~h}$ after hCG (B) in embryos cultured with glucose (A), or receiving a glucose 'pulse' (C) Magnification $\sim \times 300$. MCT1 mRNA was not detected in morulae cultured in the absence of glucose, but was present in morulae exposed to glucose either continuously or via a brief glucose pulse (E).

\section{Discussion}

\section{Expression of MCT during preimplantation development}

We have used RT-PCR to demonstrate, for the first time, MCT protein expression and localisation in embryos. While MCT1 mRNA and protein are expressed from the zygote to the blastocyst stage, MCT3 could not be detected as mRNA or protein. Expression of MCT1, MCT2 and MCT4 mRNA has previously been demonstrated throughout preimplantation development in the mouse (Harding et al. 1999, Herubel et al. 2002). However, there is conflict over the expression of MCT3 mRNA in developing mouse embryos. While Harding et al. (1999) report mRNA expression for MCT3, our results confirm those of Herubel et al. (2002), who found that MCT3 is absent during this period of development.

MCT1 is ubiquitously distributed in tissues (Garcia et al. 1994, Jackson et al. 1997, Wilson et al. 1998). It can catalyse the exchange of one monocarboxylate for another, or net transport of a monocarboxylate along with a proton in either direction across the cell membrane (Halestrap \& Meredith 2004). This suggests that MCT1 plays an important role in regulating intracellular lactate and pyruvate to balance nutrient, $\mathrm{pH}$ and redox status. Pyruvate is required for the first cleavage division in mouse embryos (Biggers et al. 1967, Leese \& Barton 1984), so the appearance of MCT1 in early preimplantation development was not surprising.

While MCT1 is generally localised to the plasma membrane (Philp et al. 1998, 2003a, 2003b, Bergersen et al. 1999, Fanelli et al. 2003, Clamp et al. 2004), tissue fractionation has revealed MCT1 in sarcoplasmic reticulum, T-tubules, triads, and intracellular membranes of rat heart and skeletal muscle (Bonen et al. 2000) and in rat liver peroxisomes (McClelland et al. 2003). These data are consistent with our finding that MCT1 immunoreactivity, while it appears brighter in the cytoplasmic cortex of cleavage-stage embryos, persists diffusely in the cytoplasm of morulae and early blastocysts. This suggests that MCT1 may reside in a cytoplasmic vesicular pool, possibly in mitochondria or peroxisomes.

Cytoplasmic staining of MCT1 appears to be less diffuse in expanding blastocysts, with clear localisation to the cytoplasmic cortex. This suggests that MCT1 becomes more important for rapid monocarboxylate exchange at this stage of development. While present throughout ICM and TE cells, the highest intensity of MCT1 
A

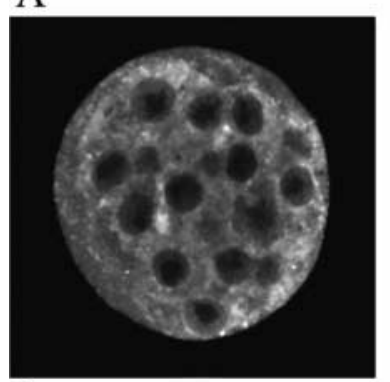

E

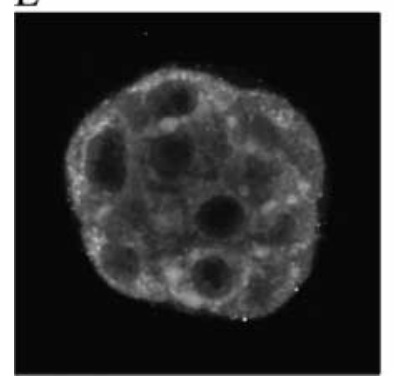

B

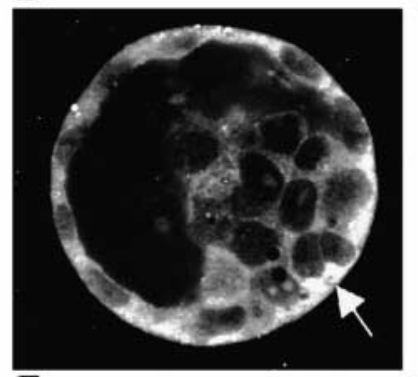

F

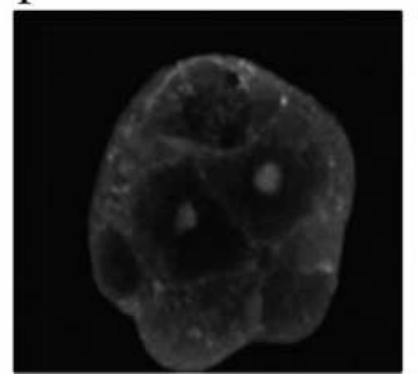

C

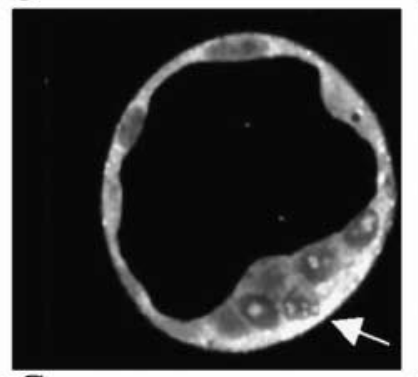

G

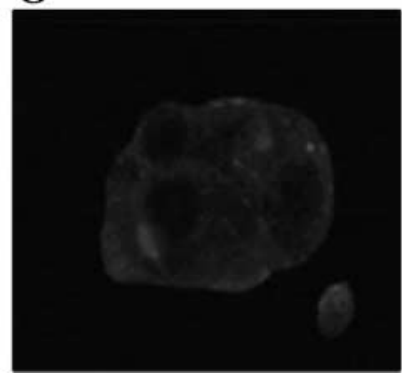

D

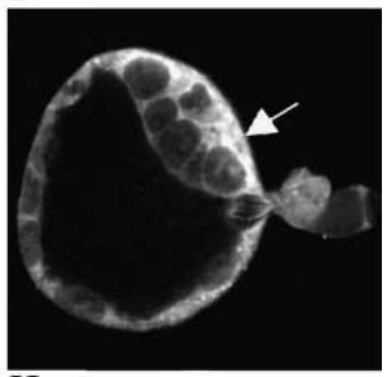

$\mathrm{H}$

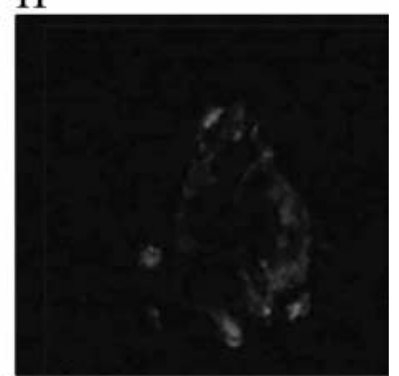

Figure 8 Effect of glucose on MCT1 expression in cultured mouse embryos. Zygotes (18 h after hCG) were cultured in KSOM (A-D) or KSOM$\mathrm{G}(\mathrm{E}-\mathrm{H})$. Embryos were collected at 90, 98, 105 and $112 \mathrm{~h}$ after hCG for immunohistochemical analysis of MCT1. Culture in the presence of glucose at 90 (A), 98 (B), 105 (C) and $112 \mathrm{~h}$ after hCG (D) demonstrates that immunoreactivity to MCT1 protein becomes more intense at the polar TE in expanding and hatching blastocysts (arrows: B-D) with loss of nuclear localisation (D). Without glucose, MCT1 immunoreactivity diminishes from 90 (E) and $98 \mathrm{~h}$ after hCG (F) to barely detectable levels at 105 (G) and $112 \mathrm{~h}$ after hCG (H), concurrent with a characteristic failure to develop to a blastocyst $(\mathrm{G})$ and subsequent degeneration $(\mathrm{H})$. Magnification $\sim \times 300$.

immunoreactivity is in the polar TE. Glucose utilisation via glycolysis in blastocysts results in lactic acid accumulation in cells and in the blastocoel cavity (Brison et al. 1993). In the mouse, the polar TE contacts the uterine wall before further differentiation of the TE into cytotrophoblast and invading syncytiotrophoblast. Polarisation of MCT1 to this region around the time of implantation may optimise rapid exchange of pyruvate/lactate with the developing fetal-maternal circulation. Indeed, MCT1 has been localised to the basement membrane of human term placenta, and is thus well positioned for a role in fetal-maternal exchange (Settle et al. 2004). Efflux of $\mathrm{H}^{+}$ would also enable $\mathrm{pH}$ homeostasis for continued development, and prevent inhibition of glycolytic enzymes (e.g. 6-phosphofructokinase) (Barbehenn et al. 1974, Kusen et al. 1975), thereby allowing glycolysis to continue.

MCT3 transports lactate with higher affinity than pyruvate and is considered to be important in $\mathrm{pH}$, nutrient and fluid homeostasis in retinal pigment epithelium (Yoon et al. 1997, Philp et al. 1998, 2001, 2003a). The retina, like blastocysts, predominantly metabolises glucose via glycolysis and achieves the vectorial transport of fluid and metabolites by development of tight junctions between epithelial cells, and polarised distribution of transport proteins (Philp et al. 1998, 2003a). MCT3 exists on the basolateral membrane, and MCT1 on the apical membrane of retinal epithelial cells for the cooperative, unidirectional transport of excess lactate from the subretinal space to the systemic circulation (Philp et al. 1998). We proposed that blastocysts might have a similar polarised distribution of MCT1 and MCT3 to export lactate from the blastocoel cavity and ICM to the external environment. MCT3 has not been located outside the retina, except for reports of mRNA expression in preimplantation embryos (Harding et al. 1999).

Immunohistochemical analysis of MCT3 revealed immunoreactivity at a level similar to normal rabbit serum controls, indicating that this protein isoform may not be present in early mouse embryos, or that it is expressed at much lower levels than MCT1. This finding is supported by the absence of MCT3 mRNA and is consistent with the findings of Herubel et al. (2002).

\section{Lactate uptake in preimplantation embryos}

Lactate transport via MCT involves the initial binding of a proton followed by the lactate anion, which are then translocated across the membrane and subsequently released. This process is freely reversible (Halestrap \& Price 1999). In these experiments, lactate uptake reached a plateau as quickly as $12 \mathrm{~min}$ in some embryos, at concentrations of 5 and $25 \mathrm{mmol}$ DL-lactate/l. This is probably due to bidirectional transport via the MCT according to the following formula: [lactate] $\mathrm{in} /[$ lactate $]$ out $=\left[\mathrm{H}^{+}\right]$ out/[ $\left.\mathrm{H}^{+}\right]$in. It is also possible that a low $\mathrm{pHi}$ or increasing intracellular lactate generated by $\mathrm{H}^{+}$/lactate influx decreased the rate of DL-lactate uptake to effect a steady state by this time. 
The results show that MCT transport in preimplantation embryos is concentration dependent and follows Michaelis-Menten kinetics. The decrease in $K_{\mathrm{m}}$ with constant $V_{\max }$ during development contrasts with an earlier study which used fluorescent $\mathrm{pH}$ fluctuations as a measure of lactate transport (Harding et al. 1999). MCT kinetics in mouse embryos were reported to demonstrate a constant $K_{\mathrm{m}}$ with an increase in $V_{\mathrm{ma}}$ during development that was significant on regression analysis $(P<0.01)$ (Harding et al. 1999). One explanation for this difference is that the previous study used a medium in which all anions had been replaced with the impermeant anion gluconate, causing $\mathrm{H}^{+}$efflux and a subsequent increase in pHi. It is known that creating high $\mathrm{pHi}$ with respect to the extracellular environment increases the $V_{\max }$ of MCT transport (Halestrap \& Price 1999), and this may have amplified any minor developmental changes in $V_{\text {ma }}$ to show a significant effect.

With the $\left[{ }^{3} \mathrm{H}\right] \mathrm{DL}$-lactate uptake assay at physiological $\mathrm{pH}(7.4)$ and in the presence of $25 \mathrm{mmol} / \mathrm{l}$ pyruvate, blastocysts demonstrated a significantly lower $K_{\mathrm{m}}$ than earlier preimplantation stages. At physiological concentrations of around $5 \mathrm{mmol}$ lactate/l (Gardner \& Leese 1990) and $10 \mathrm{mmol}$ lactate/l in standard KSOM (Lawitts \& Biggers 1993), blastocysts would be almost twice as active in lactate uptake as cleavage-stage embryos. There is evidence that increasing lactate concentrations in culture causes a decrease in $V_{\mathrm{ma}}$ for pyruvate uptake at all preimplantation stages, and this has been attributed to competition by both substrates for MCT (Lane \& Gardner 2000). The effect was more marked in the blastocyst (Lane \& Gardner 2000). This observation, and the reduced $K_{\mathrm{m}}$ of blastocysts indicating increased affinity for lactate, may reflect the concentration of MCT1 to the polar TE of expanding and hatching blastocysts. However, changes in the affinity or $K_{\mathrm{m}}$, but not $V_{\max }$ as the embryos develop, is more likely to suggest a variation in the expression of other MCT protein isoforms at later preimplantation stages, although this has not yet been reported, and no evidence for MCT3 was obtained. Both PCR and immunohistochemical data support the observation that there are no differences in the molecular characteristics of MCT transport between embryos developing in vivo and in vitro.

\section{Effect of glucose on MCT expression}

The persistent uptake of DL-lactate demonstrates net activity of MCT throughout preimplantation development. These data complement observations that lactate and pyruvate may sustain blastocyst formation when embryos are cultured from the two-cell stage in the absence of glucose (Martin \& Leese 1995). However, while culture in glucose-free medium from the eight-cell stage did not appear to affect the activity of MCT (Harding et al. 1999), previous studies demonstrated earlier effects of glucose on pyruvate metabolism and preimplantation embryo physiology (Chatot et al. 1989, Brown \& Whittingham 1991,
Martin \& Leese 1999, Pantaleon et al. 2001a, 2001b). In this investigation, culture in the absence of glucose from the zygote stage reduced MCT1 mRNA expression by $90 \mathrm{~h}$ after hCG, with a subsequent decrease in MCT1 protein levels. Embryos receiving a brief exposure to glucose around the four-cell stage of development, however, retained their ability to express MCT1 in a subsequent glucose-free environment. Unfortunately, these observations were not supported by a significant difference in lactate transport under varying conditions of glucose exposure, probably because of a lack of sensitivity in this approach.

The DL-lactate uptake assay did not detect a change in net lactate uptake rates, probably because of the high variance of the $V_{\max }$ estimates. Mixed D- and L-isomers were used in the assay, and this may have contributed to the difficulty in detecting small differences in uptake rates. MCT1 is stereospecific for lactate, and $K_{\mathrm{m}}$ for the L-isomer is an order of magnitude lower than for the D-isomer (Broer et al. 1998, Manning Fox et al. 2000). Of the available lactate in the media, 50\% was D-lactate, possibly masking any measurable changes in $K_{\mathrm{m}}$. The coexpression of other MCT isoforms cannot be excluded, and this may also have affected net lactate uptake. The transport assay employed could not resolve the contribution of multiple MCT isoforms.

Nevertheless, results are consistent with metabolic studies reporting that embryos deprived of glucose from the zygote stage demonstrate a continual decline in both glucose and pyruvate utilisation from around $90 \mathrm{~h}$ after hCG until they eventually degenerate (Martin \& Leese 1995, 1999). The data also complement studies that demonstrate a similar glucose-activated expression of GLUT3, a high-affinity glucose transporter. Taken together, these results support the hypothesis that glucose acts as a metabolic signal to cleavage-stage embryos, permitting the expression of metabolic enzymes required for blastocyst formation (Chatot et al. 1994, Pantaleon et al. 1997a, Pantaleon \& Kaye 1998).

\section{Conclusion}

This investigation confirms the presence of MCT1 and absence of MCT3 mRNA during preimplantation development, and demonstrates MCT1 (but not MCT3) protein localisation for the first time in embryos. Cleavage-stage exposure to glucose is required for persistent MCT1 expression. Culture without glucose from the zygote stage leads to complete absence of MCT1 mRNA and a gradual decline in protein coincident with degeneration. Embryos cultured with glucose, or briefly exposed to glucose at the four-cell stage, retain MCT1 mRNA and protein expression. These data are consistent with previous observations of transporter expression and pyruvate utilisation in the presence and absence of glucose, and support the hypothesis that glucose is important as a signalling molecule for metabolic differentiation in the preimplantation embryo. 


\section{Acknowledgements}

We thank Dr Nancy Philp (Thomas Jefferson University, Philadelphia, USA) for her generous gift of antibodies. This research was supported by grants to $P L K$ and $M P$ from the National Health and Medical Research Council of Australia (grant no. 210194) and the NICHD (grant no. U01 HD 44664). The authors declare that there is no conflict of interest that would prejudice the impartiality of this scientific work.

\section{References}

Arcellana-Panlilio MY, \& Schultz GA 1993 Analysis of messenger RNA. Methods in Enzymology 225 303-328.

Barbehenn EK, Wales RG \& Lowry OH 1974 The explanation for the blockade of glycolysis in early mouse embryos. PNAS 71 1056-1060.

Bergersen L, Johannsson E, Veruki ML, Nagelhus EA, Halestrap A, Sejersted OM \& Ottersen OP 1999 Cellular and subcellular expression of monocarboxylate transporters in the pigment epithelium and retina of the rat. Neuroscience 90 319-331.

Biggers JD, Whittingham DG \& Donahue RP 1967 The pattern of energy metabolism in the mouse oocyte and zygote. PNAS $\mathbf{5 8}$ 560-567.

Bonen A, Miskovic D, Tonouchi M, Lemieux K, Wilson MC, Marette A \& Halestrap AP 2000 Abundance and subcellular distribution of MCT1 and MCT4 in heart and fast-twitch skeletal muscles. American Journal of Physiology. Endocrinology and Metabolism 278 E1067-E1077.

Brinster RL \& Thomson JL 1966 Development of eight-cell mouse embryos in vitro. Experimental Cell Research 42 308-315.

Brison DR, Hewitson LC \& Leese HJ 1993 Glucose, pyruvate, and lactate concentrations in the blastocoel cavity of rat and mouse embryos. Molecular Reproduction and Development 35 227-232.

Broer S, Schneider HP, Broer A, Rahman B, Hamprecht B \& Deitmer JW 1998 Characterization of the monocarboxylate transporter 1 expressed in Xenopus laevis oocytes by changes in cytosolic $\mathrm{pH}$. Biochemical Journal 333 Pt 1 167-174.

Brown JJ \& Whittingham DG 1991 The roles of pyruvate, lactate and glucose during preimplantation development of embryos from F1 hybrid mice in vitro. Development 112 99-105.

Chatot CL, Ziomek CA, Bavister BD, Lewis JL \& Torres I 1989 An improved culture medium supports development of random-bred 1-cell mouse embryos in vitro. Journal of Reproductive Fertility $\mathbf{8 6}$ 679-688.

Chatot CL, Lewis-Williams J, Torres I \& Ziomek CA 1994 One-minute exposure of 4-cell mouse embryos to glucose overcomes morula block in CZB medium. Molecular Reproduction and Development 37 407-412.

Clamp MF, Ochrietor JD, Moroz TP \& Linser PJ 2004 Developmental analyses of 5A11/Basigin, 5A11/Basigin-2 and their putative binding partner MCT1 in the mouse eye. Experimental Eye Research $\mathbf{7 8}$ 777-789.

Fanelli A, Grollman EF, Wang D \& Philp NJ 2003 MCT1 and its accessory protein $\mathrm{CD} 147$ are differentially regulated by $\mathrm{TSH}$ in rat thyroid cells. American Journal of Physiology. Endocrinology and Metabolism 285 E1223-E1229.

Fulton BP \& Whittingham DG 1978 Activation of mammalian oocytes by intracellular injection of calcium. Nature 273 149-151.

Garcia CK, Goldstein JL, Pathak RK, Anderson RG \& Brown MS 1994 Molecular characterization of a membrane transporter for lactate, pyruvate, and other monocarboxylates: implications for the Cori cycle. Cell 76 865-873.

Gardner DK \& Leese HJ 1986 Non-invasive measurement of nutrient uptake by single cultured pre-implantation mouse embryos. Human Reproduction 1 25-27.

Gardner DK \& Leese HJ 1990 Concentrations of nutrients in mouse oviduct fluid and their effects on embryo development and metabolism in vitro. Journal of Reproductive Fertility $\mathbf{8 8}$ $361-368$.

Gardner HG \& Kaye PL 1995 Characterization of glucose transport in preimplantation mouse embryos. Reproduction, Fertility, and Development 7 41-50.

Gould GW \& Holman GD 1993 The glucose transporter family: structure, function and tissue-specific expression. Biochemistry Journal 295 (Pt 2) 329-341.

Halestrap AP 1976 Transport of pyruvate and lactate into human erythrocytes. Evidence for the involvement of the chloride carrier and a chloride-independent carrier. Biochemical Journal 156 193-207.

Halestrap AP \& Price NT 1999 The proton-linked monocarboxylate transporter (MCT) family: structure, function and regulation. Biochemical Journal 343 (Pt 2) 281-299.

Halestrap AP \& Meredith D 2004 The SLC16 gene family - from monocarboxylate transporters (MCTs) to aromatic amino acid transporters and beyond. Pflugers Archiv 447 619-628.

Harding EA, Day ML, Gibb CA, Johnson MH \& Cook DI 1999 The activity of the $\mathrm{H}^{+}$-monocarboxylate cotransporter during preimplantation development in the mouse. Pflugers Archiv $\mathbf{4 3 8}$ 397-404.

Herubel F, El Mouatassim S, Guerin P, Frydman R \& Menezo Y 2002 Genetic expression of monocarboxylate transporters during human and murine oocyte maturation and early embryonic development. Zygote 10 175-181.

Hobbs JG \& Kaye PL 1985 Glycine transport in mouse eggs and preimplantation embryos. Journal of Reproduction and Fertility $\mathbf{7 4}$ $77-86$.

Jackson VN, Price NT, Carpenter L \& Halestrap AP 1997 Cloning of the monocarboxylate transporter isoform MCT2 from rat testis provides evidence that expression in tissues is species-specific and may involve post-transcriptional regulation. Biochemical Journal 324 Pt 2 447-453.

Kusen SI, Solohub LI, Olexyn HO \& Sen'kus YT 1975 Enzymes of glycolysis and pentosephosphate shunt during early embryogenesis of the loach and the effect of glucose, lactate and fumarate on fertilized oocytes. Ukrains'kyi biokhimichnyi zhurnal 47 $448-452$

Laemmli UK 1970 Cleavage of structural proteins during the assembly of the head of bacteriophage T4. Nature 227 680-685.

Lane M \& Gardner DK 2000 Lactate regulates pyruvate uptake and metabolism in the preimplantation mouse embryo. Biology of Reproduction 62 16-22.

Lawitts JA \& Biggers JD 1993 Culture of preimplantation embryos. Methods in Enzymology 225 153-164.

Leese HJ \& Barton AM 1984 Pyruvate and glucose uptake by mouse ova and preimplantation embryos. Journal of Reproduction and Fertility 72 9-13.

Manning Fox JE, Meredith D \& Halestrap AP 2000 Characterisation of human monocarboxylate transporter 4 substantiates its role in lactic acid efflux from skeletal muscle. Journal of Physiology $\mathbf{5 2 9}$ Pt 2 285-293.

Martin KL \& Leese HJ 1995 Role of glucose in mouse preimplantation embryo development. Molecular Reproduction and Development 40 436-443.

Martin KL \& Leese HJ 1999 Role of developmental factors in the switch from pyruvate to glucose as the major exogenous energy substrate in the preimplantation mouse embryo. Reproduction, Fertility, and Development 11 425-433.

McClelland GB, Khanna S, Gonzalez GF, Butz CE \& Brooks GA 2003 Peroxisomal membrane monocarboxylate transporters: evidence for a redox shuttle system? Biochemical and Biophysical Research Communications 304 130-135.

Pantaleon M \& Kaye PL 1998 Glucose transporters in preimplantation development. Reviews in Reproduction 3 77-81.

Pantaleon M, Harvey MB, Pascoe WS, James DE \& Kaye PL 1997 a Glucose transporter GLUT3: ontogeny, targeting, and role in the mouse blastocyst. PNAS 94 3795-3800. 
Pantaleon M, Whiteside EJ, Harvey MB, Barnard RT, Waters MJ \& Kaye PL 1997b Functional growth hormone $(\mathrm{GH})$ receptors and $\mathrm{GH}$ are expressed by preimplantation mouse embryos: a role for GH in early embryogenesis? PNAS 94 5125-5130.

Pantaleon M, Scott J \& Kaye PL 2001a Glucose signals through the hexosamine biosynthetic pathway in mouse preimplantation embryos. SRB: Proceedings of the Thirty-Second Annual Conference, Gold Coast QLD, Abstract no. 42.

Pantaleon M, Ryan JP, Gil M \& Kaye PL 2001b An unusual subcellular localization of GLUT1 and link with metabolism in oocytes and preimplantation mouse embryos. Biology of Reproduction 64 1247-1254.

Philp NJ, Yoon H \& Grollman EF 1998 Monocarboxylate transporter MCT1 is located in the apical membrane and MCT3 in the basal membrane of rat RPE. American Journal of Physiology 274 R1824-R1828.

Philp NJ, Yoon H \& Lombardi L 2001 Mouse MCT3 gene is expressed preferentially in retinal pigment and choroid plexus epithelia. American Journal of Physiology. Cell Physiology $\mathbf{2 8 0}$ C1319-C1326.

Philp NJ, Wang D, Yoon H \& Hjelmeland LM 2003a Polarized expression of monocarboxylate transporters in human retinal pigment epithelium and ARPE-19 cells. Investigations in Ophthalmological and Visceral Science 44 1716-1721.

Philp NJ, Ochrietor JD, Rudoy C, Muramatsu T \& Linser PJ 2003b Loss of MCT1, MCT3, and MCT4 expression in the retinal pigment epithelium and neural retina of the 5A11/basigin-null mouse. Investigations in Ophthalmological and Visceral Science $\mathbf{4 4}$ 1305-1311.

Price NT, Jackson VN \& Halestrap AP 1998 Cloning and sequencing of four new mammalian monocarboxylate transporter (MCT) homologues confirms the existence of a transporter family with an ancient past. Biochemical Journal 329 (Pt 2) 321-328.

Settle P, Mynett K, Speake P, Champion E, Doughty IM, Sibley CP, D'Souza SW \& Glazier J 2004 Polarized lactate transporter activity and expression in the syncytiotrophoblast of the term human placenta. Placenta 25 496-504.

Telford NA, Hogan A, Franz CR \& Schultz GA 1990 Expression of genes for insulin and insulin-like growth factors and receptors in early postimplantation mouse embryos and embryonal carcinoma cells. Molecular Reproduction and Development 27 $81-92$.

Towbin H, Staehelin T \& Gordon J 1979 Electrophoretic transfer of proteins from polyacrylamide gels to nitrocellulose sheets: procedure and some applications. PNAS 76 4350-4354.

Wilson MC, Jackson VN, Heddle C, Price NT, Pilegaard H, Juel C, Bonen A, Montgomery I, Hutter OF \& Halestrap AP 1998 Lactic acid efflux from white skeletal muscle is catalyzed by the monocarboxylate transporter isoform MCT3. Journal of Biological Chemistry 273 15920-15926.

Yoon H, Fanelli A, Grollman EF \& Philp NJ 1997 Identification of a unique monocarboxylate transporter (MCT3) in retinal pigment epithelium. Biochemical and Biophysical Research Communications 234 90-94.

Received 6 September 2005

First decision 4 October 2005

Revised manuscript received 26 October 2005

Accepted 17 November 2005 